\title{
Ensinar histórias menores: narrativas e memórias de auxiliares de serviços gerais escolares na busca de relações outras
}

\author{
Teach minor histories: narratives and memories of school cafeteria workers in the \\ search of other relationships
}

\author{
Maria Cecília Paladini Piazza \\ Doutoranda em Educação pela Universidade Federal de Santa Catarina \\ cissapiazza@yahoo.com.br \\ Giovanna Santana \\ Doutoranda em Educação pela Universidade Federal de Santa Catarina \\ giovanna_santana@hotmail.com.br
}

\begin{abstract}
Resumo: Este artigo dialoga com narrativas de quatro mulheres auxiliares de serviços gerais de uma escola estadual no município de Araranguá, Santa Catarina. O objetivo de escutá-las surge como uma maneira de disseminar outra postura epistemológica em relação aos conhecimentos tradicionalmente valorizados pelos currículos oficiais, buscando com apoio do ensino de História evidenciar suas contribuições como educadoras. $\mathrm{O}$ estudo se desenvolveu a partir da análise de fontes narrativas, bibliográficas e documentais. Metodologicamente está fundamentado na concepção de mônada, extraída do pensamento de Walter Benjamin, e impulsionado por leituras decoloniais. Considera-se que é possível estimular dentro da perspectiva historiográfica uma Pedagogia da Memória, com a insurgência de histórias menores em contraposição ao pensamento hegemônico da história maior, narrativa estrutural distante da realidade dos estudantes e dos sujeitos presentes na comunidade escolar.
\end{abstract}

Palavras-chave: Auxiliares de serviços gerais escolares, Ensino de História, Decolonialidade.

\begin{abstract}
This article dialogues with narratives of four womens, servents and school cafeteria workers at one state school in Araranguá, Santa Catarina. The objective of listening to them emerges as a way to disseminate another epistemological stance in relation to the knowledge traditionally valued by official curricula, seeking with the support of History teaching to highlight their contributions as educators. The study was developed from the analysis of narratives, bibliographic and documentary sources. It's based on the concept of monad, extracted from Walter Benjamin, and guided by decolonial thinking. It's considered that it's possible to stimulate a Pedagogy of Memory, with the insurgency of minor histories in opposition to the hegemonic thinking of the larger history, a structural narrative distant from the reality of students and subjects presents in the school community.
\end{abstract}

Keywords: School cafeteria workers, History teaching, Decoloniality. 


\section{Introdução}

Neste artigo dialogamos com as narrativas orais de quatro mulheres brancas que compõem o grupo de auxiliares de serviços gerais da EEB Prof Neusa Ostetto Cardoso do município de Araranguá, no bairro Polícia Rodoviária, Santa Catarina, enfatizando seus diferentes saberes, fazeres e experiências educativas não formalizadas. Nas entrevistas, muito disseram de si, de seus sonhos e de suas angústias. Para essa abertura, tivemos que repensar nossa metodologia de entrevistas e buscar estratégias outras de pesquisar em campo.

As entrevistas fazem parte de uma tese de doutorado em desenvolvimento, intitulada "Por entre corredores e refeitórios: escovando narrativas e memórias de auxiliares de serviços gerais escolares na busca de relações outras", desenvolvida no Programa de Pós-graduação em Educação da Universidade Federal de Santa Catarina, que tem como objetivo a valorização de saberes no cotidiano escolar, destacando a importância do ofício exercido pelas auxiliares de serviços gerais e suas funções que estão além daquelas prescritas nos documentos oficiais.

Vale ressaltar que são poucas as pesquisas em Educação com recorte neste grupo social, o que aponta para a pouca visibilidade que lhes é atribuída. Nesse sentido, destacamos aqui o trabalho de Marina Luz Rotava Paim, dissertação de mestrado defendida em 2017, que aborda as experiências de zeladores e serventes da cidade de Chapecó-SC e suas potencialidades para a construção de conhecimento histórico, a dissertação de Diogo Lopes Silva (2014) abordando as representações das/os trabalhadores não docentes no cotidiano escolar e as pesquisas da historiadora Fátima Machado Chaves (2000) desenvolvidas nas escolas municipais do Rio de Janeiro, intersecionadas com a área da Saúde Pública. Também neste campo temos as pesquisas de Bernadete de Oliveira Nunes (2000), a respeito dos sentidos atribuídos aos trabalhos de serventes e de merendeiras em situação de readaptação, e na área da Psicologia do Trabalho, pesquisas orientadas por Ana Cláudia Leal de Vasconcelos (2002; 2014).

De acordo com tais estudos,

[...] uma das principais fontes de sofrimento psíquico é o não reconhecimento por parte dos outros profissionais da escola, do trabalho e do papel de educadoras que as merendeiras e serventes exercem. Pois, tanto as merendeiras quanto as auxiliares de serviço ensinam aos alunos bons modos, 
como devem se alimentar e a se preocuparem com a higiene. Porém, como a atividade de merendeiras e serventes são consideradas como qualidades naturais femininas (cozinhar e limpar), acaba havendo o não reconhecimento do valor e da complexidade da atividade destas trabalhadoras [...]. (VASCONCELOS et al., 2002)

Além dos aspectos apontados no trecho, acrescentamos a desvalorização do trabalho braçal/manual, característica da sociedade moderna capitalista, e outras dimensões do cotidiano desveladas no decorrer das entrevistas, que dizem respeito ao afeto e ao acolhimento que elas agregam no universo escolar, também situados na esfera do trabalho feminino não remunerado. Vale destacar que esta generosidade muitas vezes não lhes é retribuída, como mostra a narração que deu origem ao processo de pesquisa, momento no qual uma das entrevistadas relata que "só lembram de nós quando é para cozinhar".

Diante desta situação, como reconhecê-las enquanto sujeitos que participam efetivamente do ensino em espaços informais da escola? Como extrair problemáticas atuais nas sutilezas de suas narrativas? Como romper com a hierarquia de saberes e atribuir às auxiliares de serviços gerais um espaço de protagonismo no ambiente escolar? E qual o papel do ensino de História diante deste desafio?

Tendo em vista estes aspectos, a opção metodológica foi trabalhar com autores e autoras que contribuem para a superação das condições vigentes. Dentre eles, Walter Benjamin, que nos fornece ferramentas teóricas para o trabalho com as fontes narrativas a partir da abordagem monadológica, fazendo despertar no presente a possibilidade de um outro por vir. Nossa motivação é estimular na perspectiva historiográfica a insurgência de histórias menores em contraposição ao pensamento único e hegemônico da história maior, como narrativa eurocentrada e distante da realidade dos estudantes e dos sujeitos presentes na comunidade escolar. Por história menor nos referimos ao artigo de Nilton Mullet Pereira (2018) que propõe o uso do termo como chave de leitura para transcender o paradigma das grandes estruturas e das macronarrativas predominantes no ensino de História.

Debruçadas em leituras da decolonialidade, encontramos fundamentos para questionar a reprodução das colonialidades do ser, do saber e do poder, que são responsáveis pela manutenção das opressões e dos privilégios no tempo presente (QUIJANO, 2007). Nesse sentido, valorizar as auxiliares de serviços gerais também 
atravessa a construção de uma escola com mais consciência política, o que no campo da História implica em assumir uma postura epistemológica crítica em relação aos conhecimentos tradicionalmente validados pelos currículos escolares.

\section{Apresentando a escola}

O local da pesquisa está situado na cidade de Araranguá, conhecida como a "Cidade das Avenidas". Pertence a Microrregião do Extremo Sul Catarinense e sua população, de acordo com o IBGE (Instituto Brasileiro de Geografia e Estatísticas) são de sessenta e três mil habitantes. Além disso, a cidade é banhada pelo Rio Araranguá e está localizada bem próxima da BR-101. Possui comércio intenso, agricultura na produção de arroz irrigado, fumo, milho, entre outras culturas.

A Unidade Escolar denominada Escola de Educação Básica Professora Neusa Ostetto Cardoso localiza-se na rua Eduardo Generoso Pereira, no bairro Polícia Rodoviária, município de Araranguá-SC. A instituição é mantida pelo Estado de Santa Catarina e administrada pela Secretaria de Estado da Educação. Oferece Ensino Fundamental de nove anos, Ensino Médio nos turnos matutino, vespertino e noturno, com aproximadamente 600 discentes.

A escola fica próxima a BR 101, sendo a comunidade do bairro Polícia Rodoviária um aglomerado urbano, rural com baixa renda per-capta e com problemas na infraestrutura. Há uma grande rotatividade de moradoras/es, pois a unidade escolar fica próxima ao presídio e muitas pessoas se mudam para poder ficar perto de seus entes em reclusão. Além disso, segundo o Projeto Político Pedagógico (PPP) da unidade, a oferta de emprego é insuficiente para atender as necessidades da população local. Ao mesmo tempo, há uma forte rede de prostituição e tráfico de drogas.

Os recursos físicos que agregam a instituição são: dez salas de aula; uma secretaria; duas cozinhas; um ginásio de esportes; sete banheiros; uma sala de professoras/es, um refeitório; e uma sala de atendimento pedagógico. A rua não possui calçamento e as auxiliares sempre reclamam da quantidade de poeira e da dificuldade em manter a escola limpa.

Além do mais, as salas de aula se encontram em estado de degradação, apresentam péssima qualidade de iluminação natural e artificial à noite. As lâmpadas 
queimam com facilidade, pois a instalação elétrica está muito precária e antiga. De

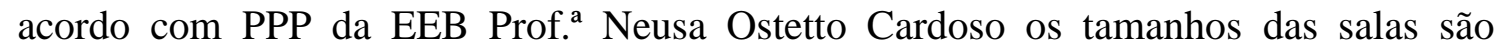
variados e nem sempre dentro dos padrões estabelecidos pela resolução 90/99, artigos $9^{\circ}$ e $12^{\circ}$.

O corpo administrativo da escola é formado por uma gestora, duas/ois assessoras/es, dois assistentes de educação e três assistentes técnico pedagógico. Contamos com uma equipe de quarenta e oito docentes. E nos serviços gerais temos as narradoras protagonistas deste artigo: C. P. S., L. P. K., E. S. C., M. J. D.

Segundo o PPP, os serviços gerais compreendem a conservação, a vigilância, a limpeza, a copa/cozinha que serão supervisionados pela gestora escolar. As funcionárias da limpeza são contratadas pelo regime da Consolidação das Leis do Trabalho (CLT) e/ou Concurso Público, respeitando-se a legislação vigente, através da Associação de Pais e Professores (APP). Desse modo, é atribuição da APP a contratação de auxiliares de serviços gerais, pelo regime da Lei Trabalhista (CLT), por meio de convênios com a Gerência Regional de Educação, a qual assumirá o ônus financeiro.

Ainda, de acordo com o PPP, compete às serventes escolares: zelar pela limpeza e conservação de todas as dependências da escola; manter o serviço de copa/cozinha de acordo com as determinações da instituição, colaborar com a manutenção do prédio escolar; manter em estado de higiene os sanitários, calçadas, áreas de lazer, pátios, salas, cozinha, janelas e abrir e fechar o estabelecimento no horário previsto pela gestora da escola.

Há também a equipe do Grupo Risotolândia, que é terceirizada, porém no horário do recreio, devido à alta demanda de estudantes, as auxiliares de serviços gerais prepararam e servem a merenda escolar. Em nossas conversas, elas me narraram que com a vinda da Risotolândia melhorou bastante, pois não as sobrecarrega tanto, já que antes da instalação, ficavam com toda responsabilidade para limpar a escola, preparar a alimentação das/os estudantes e servir as refeições. Agora são responsáveis na hora de servir as/os discentes e higienizam a escola.

Cabe contextualizar que a dinâmica na escola ocorre da seguinte maneira: C. e L. trabalham no período vespertino, chegam à escola perto do meio dia e terminam o expediente por volta de cinco e meia da tarde. Após todos irem embora, elas organizam as salas.

L. tem sessenta anos de idade, tem três filhos, é casada e trabalha na escola há dezoito anos. C. tem quarenta e cinco anos, sendo a mais nova, tem dois filhos, namora 
e está conosco há quinze anos. E. e M. J. fazem a parceria no período matutino, chegam por volta das sete da manhã e retornam para suas casas meio dia e trinta. Coincidentemente, ambas têm sessenta anos de idade, dois filhos e estão na escola há vinte anos. Todo esse tempo dedicado a deixar não só a escola mais organizada e limpa, mas também a iluminar o nosso cotidiano com suas experiências, conselhos e saberes. Eu as conheço já fazem doze anos. Receberam-me com muito carinho na escola e logo já criamos um vínculo que ultrapassava questões de hierarquia.

\section{Diálogo com as mônadas}

Antes de começar a coleta das narrativas, o projeto de pesquisa foi submetido ao Comitê de Ética da Universidade Federal de Santa Catarina, seguindo as exigências e as prescrições orientadas pelo órgão. Apresentados os objetivos, os pesquisadores responsáveis e as condições para a realização da mesma, a autorização foi concedida sob o número do protocolo 3.418 .817 no dia vinte e sete de novembro de 2019 , quando se deu início ao agendamento dos encontros.

As conversas com C., L., E. e M. J. ocorreram inicialmente na escola, local de trabalho, porém nessas primeiras ocasiões as narradoras não conseguiram desabrochar em suas falas. Resolvemos fazer um encontro em casa, também localizada na cidade de Araranguá, onde estiveram presentes no dia dois de dezembro de 2019, Maria Cecília Paladini Piazza, como anfitriã e pesquisadora, e as entrevistadas M. J. e E.. A dinâmica funcionou bem na medida em que dispomos de uma mesa farta e mais privacidade, a conversa fluiu com leveza. Desse modo, ainda que seguindo um roteiro previamente estruturado, as entrevistas foram conduzidas em tom de diálogo e duraram a tarde toda, ora falavam todas de uma vez, pois estavam ávidas por narrar e serem ouvidas. Tendo em vista o resultado positivo, decidimos realizar as entrevistas em duplas. Já com a C. e a L. fizemos inicialmente na escola, havíamos marcado para abril, mas devido à pandemia do COVID-19 tivemos que cancelar.

Seguindo os protocolos de distanciamento social orientados pela Organização Mundial da Saúde nos reunimos em um espaço público no dia 19 de outubro de 2020.

Após a gravação das entrevistas em áudio foi feito o processo de transcrição, realizado por Giovanna Santana, colega e parceira do grupo de pesquisa. Enquanto 
coletivo, estrategicamente, escolhemos trabalhar com as narrativas no formato de mônadas, que têm origem no pensamento benjaminiano. Na condição de educadoras/es e de pesquisadoras/es, a monadologia nos permite falar com e não sobre as narradoras, o que nos leva a assunção de uma postura decolonial.

É bastante amplo no campo da história oral os aportes teórico-metodológicos para a análise de fontes narrativas. No entanto, algumas abordagens acabam por sobrepor a voz da/o pesquisador/a à da/o entrevistada/o, no sentido de avaliar sua veracidade, validar suas correspondências com os dados quantitativos ou até mesmo explicar a fala da/o entrevistada/o em tom de argumento científico. Outras abordagens ainda possuem a pretensão de "dar voz" ou "dar ouvidos" aos grupos marginalizados, pressupondo que estes grupos e sujeitos sequer tenham suas próprias vozes e espaços de resistência. Portanto, aqui priorizamos a dimensão da escuta, do diálogo entre diferentes formas de compreensão da realidade, na tentativa de equilibrar as relações hierárquicas que com frequência se estabelecem na educação e na pesquisa científica. De acordo com Freire (1996: 111),

Somente quem escuta paciente e criticamente o outro, fala com ele. Mesmo que, em certas condições, precise de falar a ele. O que jamais faz quem aprende a escutar para poder falar com é falar impositivamente. Até quando, necessariamente, fala contra posições ou concepções do outro, fala com ele como sujeito da escuta de sua fala crítica e não como objeto de seu discurso.

Assim, o princípio da mônada é que a sua unidade contempla uma pluralidade de interpretações, deixando em aberto a produção do conhecimento a partir da troca e do diálogo entre experiências. Tomar a construção das narrativas como mônadas significa entendê-las como histórias em fragmentos, não lineares e não cronológicas, repletas de tensões e de conflitos.

Esta opção é uma característica do grupo Patrimônio, Memória e Educação (PAMEDUC) da Universidade Federal de Santa Catarina, que desenvolve pesquisas com diferentes sujeitos e temas, elegendo a mônada como tratamento adequado para equilibrar a relação entre pesquisador/a e entrevistadas/os. São projetos que lidam com as narrativas de professoras/es de História (SOUZA, 2020; SOUZA, 2018), da educação infantil e da educação de jovens e adultos (PAIM, PAULA, 2020), das Ciências Biológicas (PINHEIRO, 2020), bem como narrativas indígenas (SANTANA, SANTANA, 2019) e narrativas carimbozeiras (OLIVEIRA, 2018). 
A potência da mônada está na percepção de que a unidade contém a totalidade, permitindo encontrar no detalhe dimensões estruturais. Logo, compreender as entrevistas como mônadas é partir do pressuposto de que elas não correspondem apenas às memórias compartilhadas de C., L., E. e M., mas de outras mulheres que vivem em situações análogas. Ainda assim, a ideia da mônada conserva a individualidade dessas narradoras e permite expressar suas subjetividades e experiências particulares. Numa relação outra de produção de conhecimento é pretendido compartilhar experiências a fim de proporcionar o reconhecimento mútuo das diferentes formas de contribuição para o processo educativo.

$\mathrm{Na}$ narrativa também encontramos a rememoração, que possui um potencial de cura, pois ao narrar estabelecemos relações com diferentes temporalidades, reelaborando a partir do presente, o passado e o futuro. Deste modo, por compartilhar o mesmo ambiente de trabalho com as narradoras pude fazer uso da rememoração como estratégia para movimentar memórias e experiências em comum. Lembro-me daquilo que me impulsionou no projeto de pesquisa para ouvir as histórias das auxiliares de serviços gerais. Foi uma vez em que sugeri, na condição de assistente pedagógica, que em uma formatura do Terceirão as auxiliares fossem homenageadas. Dos que estiveram presentes na reunião, ninguém acatou minha ideia e quem foi homenageado foi um político que nem faço questão de lembrar ou mencionar. Ali começou minha mobilização para escrever a respeito de um passado que não passou porque ainda machuca.

Trago nas mônadas abaixo, esses fragmentos que tanto me inquietam:

\section{Detalhes do cotidiano}

Para mim uma formatura de Terceirão tem que chamar quem está ali batalhando. Não é para se chamar lá o político, fulano ou ciclano. A E. principalmente né, que está sempre ali pra abrir o portão, pra fechar o portão, pra atender uma pessoa que vem entregar uma coisa, é... Sempre está ali, sábado e domingo. Um alarme que toca, daí é tu que chama (M. J., 2019).

\section{Minha estrela guia, flagrante do cotidiano}

Pois é Cecília, fico chateada porque sempre que há confraternização dos professores, só lembram de nós quando é para cozinhar, caso contrário, nem nos convidam. Estou cansada de levar panelas pra cá e pra lá, não veem que a gente também é gente [grifo das autoras] (E., 2019). 
É nítido ver que as auxiliares de serviços gerais por estarem em uma profissão com "menor prestígio" e menor exigência quanto ao nível de escolaridade têm um tratamento diferente na escola. Essa constatação é recorrente em outros estudos que abordam de distintas perspectivas o trabalho e a identidade das auxiliares de serviços gerais e das merendeiras. Além disso, historicamente a profissão tem sua origem a partir de voluntariados de mães de estudantes que cozinhavam em ambientes com pouca ou nenhuma estrutura, o que fez com que a categoria das merendeiras por muito tempo fosse considerada "desprofissionalizada" e "semidoméstica". Soma-se ao fato, a característica étnico-racial, sendo boa parte deste grupo no Brasil representado por mulheres negras (CHAVES, 2000; FERNANDES, FONSECA, SILVA, 2014).

Em nossa leitura, as estruturas que permeiam o ambiente escolar estão diretamente relacionadas aos conceitos de colonialidade do poder, do ser, do saber e do gênero (QUIJANO, 2007; LUGONES, 2008). As colonialidades do poder e do ser são matrizes impostas a partir da classificação racial e patriarcal que pautaram a distribuição de poder no colonialismo, e que perduram até os dias atuais enquanto configurações intersubjetivas, "naturalizando" as desigualdades entre brancos, negros e indígenas, homens, mulheres e transexuais, dentre outras identidades, sexualidades e formas de vida. Assim, a colonialidade do gênero é constitutiva da colonialidade do poder, uma vez que assumem uma lógica de estabelecimento mútuo. Deste conjunto, manifesta-se a colonialidade do saber, que torna o conhecimento da/o outra/o inválido, de menor valor, ou ainda a sua forma de existência invisível. Nas palavras da narradora, isso acontece a tal ponto que "não veem que a gente também é gente".

Compreender a importância da profissão que elas exercem no ambiente escolar mobiliza diferentes olhares. A visão que elas atribuem ao seu próprio trabalho, levando em conta suas subjetividades, a percepção que as/os demais trabalhadoras/es da escola atribuem às auxiliares de serviços gerais e merendeiras, e também a forma como as/os estudantes as observam.

A pesquisa de Fernandes, Fonseca e Silva (2014) sobre a alimentação escolar como espaço para educação em saúde, realizou um levantamento com as escolas municipais do Rio de Janeiro, considerando a avaliação de manipuladoras/es de alimentos sobre a intensidade do trabalho, a relação afetiva, a valorização do ofício e as ações que propiciam a educação alimentar e nutricional. A respeito da valorização do seu próprio trabalho responderam que no caso de haver falta da equipe e as preparações não poderem ser totalmente elaboradas, as/os estudantes seriam dispensados, em 
contraste com a ausência de professoras/es, que permite às/aos estudantes encaminharem outras atividades, sendo, portanto, imprescindível a presença das merendeiras para o funcionamento das escolas. Já despeito da alta intensidade das tarefas e da baixa remuneração, as/os participantes da pesquisa reconheceram que a relação afetiva com as/os estudantes e a possibilidade de lhes ofertar alimentos que muitas/os não possuem em casa mitigam os impactos negativos da profissão.

Com E. e C. aprendemos outros aspectos destes vínculos:

\section{Com tempo e calma, a memória vem}

Eu enxergo assim que a gente não tem valor! Que a gente se dedica, se dedica e faz e não tem! [...] sim, é valorizado assim pelas crianças. Então, a importância que a gente tem é que as crianças têm um amor pela gente. Nas confraternizações não dá pra gente conversar. A gente não conversa com ninguém, não aproveita nada. Porque a gente também quer conversar. Só servirmos para fazer a comida, só procuram a gente quando precisam de nós, porque na hora de convidar às vezes pra ir num passeio ou uma coisa... ninguém convida. Ninguém diz: "vamos lá comer um churrasquinho, vamos lá na pizzaria.” (E., 2019).

\section{Atitudes que nos enobrecem}

Eu gosto assim de conversar com eles. Eu converso, às vezes, tem criança que chora, chora. Eu chego e converso, eu brinco com eles. Às vezes eles vão lá tomar chá, eu digo - ah, eu vou bem né: "Agora, eu vou benzer vocês". Eles olham pra mim e começam a rir: "Agora, eu vou benzer vocês", eles riem de mim quando eu vou dar o chá (E., 2019).

\section{Diálogo e reconhecimento}

E eu acho que no fato de a gente estar ali por fora e na hora do recreio, como tu ali, conversando com eles, rindo, tudo eles acabam se sentindo mais à vontade até para se abrir, entendeu. Só no fato de, às vezes a gente nem precisa falar nada, só no fato de sentar e de escutar eles contar o problema deles, já ajuda. E a gente, eu noto assim também, que às vezes a gente acha que eles não estão nem aí para gente, mas uma de nós falta, qualquer uma falta, "ô, a tia não veio hoje por que?", sabe, “o que aconteceu com a tia?", entendeu (C., 2020). 
$\mathrm{Na}$ conversa com as narradoras fica evidente a importância que o reconhecimento tem para a melhoria da convivência no ambiente de trabalho. Essa observação também é anunciada em uma das narrativas de zeladores ouvidas por Marina L. Paim (2017: 127-128), em que se destaca a necessidade de agradecimento e da avaliação positiva sobre os serviços prestados, em detrimento das cobranças que se tornam mais recorrentes. Desta forma, o reconhecimento por parte das/os estudantes, destacados pelas auxiliares, torna-se um incentivo para realizarem suas tarefas cotidianas, ainda que o reconhecimento por parte dos demais colegas de trabalho não se manifeste de acordo com suas expectativas.

Para além das suas funções oficialmente prescritas, relatam também suas estratégias de acolhimento, pois há um alto índice de depressão entre as/os discentes, sendo que já presenciei várias vezes, elas na cozinha ou nos corredores acalentandoas/os com os saberes e experiências de vida que possuem. Estas são atividades que muitas vezes escapam da visão das/os professoras/es, as/os quais se ocupam em grande parte do tempo em cumprir com o currículo prescrito. Logo, assim como os demais sujeitos que circulam pelo ambiente escolar, as auxiliares de serviços gerais atuam em paralelo ao processo pedagógico, ampliando o currículo oculto, na medida em que socializam hábitos, valores e atitudes (SILVA, 2014).

Referente ao gênero, constructo social a respeito de quais deveriam ser os lugares e os papéis das mulheres na sociedade, no caso das merendeiras e das auxiliares de serviços gerais é também notável a relação com a maternagem, evidenciada nos trabalhos de Fernandes, Fonseca e Silva (2014) e Nunes (2000). Essa noção de familiaridade se expressa em relatos nos quais se percebe o estabelecimento de vínculos vitalícios com as/os estudantes, cujo desenvolvimento acompanham desde a infância, sendo escolhidas como madrinhas de casamento e de batismo. Conversando com E., ela nos conta:

\section{Carinho de mãe}

Aquela menina tem meio que uma tragédia né, ela tem uma trajetória bem triste, aquela menina. No ano passado quando ela estudou, a outra vez que ela estava ali, ela gritava no corredor: “Mãããe!”. Quando eu olhava era ela. Me chamou muitas vezes de mãe. A mãe morreu de câncer né, ela criou-se com a tia (E., 2019). 
É importante salientar que além da maternagem existe uma diferença cultural entre os trabalhos executados por mulheres auxiliares gerais e homens, sendo recorrente para as mulheres acumularem triplas jornadas de trabalho, pois se ocupam da escola, do trabalho doméstico e, em determinados casos, buscam outras fontes de renda. Estes fatores fazem com que as condições para o adoecimento e a necessidade de readaptação se torne mais comum para as mulheres que lidam com esses ofícios. Dos vários tipos de riscos que seus trabalhos proporcionam podemos listar queimaduras, problemas posturais relacionados ao levantamento de peso dos equipamentos, reações alérgicas aos produtos químicos, exposição diária ao calor, lesões por movimentos repetitivos, desgaste físico e emocional, entre outros (NUNES, 2000).

É nesse sentido que Silva, Melo e Vasconselos (2014) atribuíram ao seu estudo o título A astúcia invisível de mulheres trabalhadoras de escola, desenvolvido com auxiliares de serviços gerais e merendeiras das escolas públicas Manaus/AM, no intuito de identificar os mecanismos criativos que elas mobilizam para enfrentar seus desafios diários e reagir às adversidades dos seus trabalhos. A pesquisa reitera que suas atribuições envolvem habilidades como agilidade, sensibilidade, organização, coordenação, diligência, controle rigoroso do tempo, gestão coletiva do trabalho e perspicácia perante as variações como menor consumo de alimentos devido à falta das/os estudantes em dias de chuva e improvisação na falta de materiais ou equipamentos. Outra estratégia identificada foi a subversão do cardápio prescrito pela Secretaria Estadual de Educação, com a intenção de evitar o desperdício de alimentos, antecipando refeições, e administrando os insumos para oferecer comidas mais saborosas às/aos estudantes. Logo, esta experiência também constatou que elas investem potencial logístico e criativo com base em um conhecimento adquirido ao longo de suas trajetórias de vida e de trabalho. Apesar disso,

A escola na maioria das vezes não incorpora e não reconhece as experiências e as observações dessas potenciais educadoras. Esse é um tipo de trabalho que, apesar de aparentemente simples, se constitui na realidade, num trabalho difícil, complexo, que tem toda essa riqueza e que possibilita desenvolvimento e melhoria da escola pública, no sentido da assistência aos alunos, e do cuidado para eles voltado. O que observamos é que está presente na escola, como não poderia deixar de ser em uma sociedade capitalista, a divisão social do conhecimento, coincidindo com a divisão social do trabalho. Merendeiras e serventes desenvolvem um trabalho 
manual, sendo, por isso, consideradas profissionais subalternos, dos quais não se espera ou se supõe que sejam capazes de pensar ou de ter algum tipo de conhecimento a respeito de seu trabalho (NUNES, 2000: 64).

Outro aspecto levantado pela autora diz respeito à história escravocrata do país, que estruturou uma divisão social do trabalho pautada pelas estruturas intersecionadas de raça/classe/gênero implicando na subalternidade de determinados grupos sociais para além do período do colonialismo. Fazendo uma alusão à obra de Spivak (2010), questionamos se podem estas/es profissionais subalternos falar, e em diálogo com as indagações já levantadas pela dissertação de Nunes (2000: 61-67) nos perguntamos se teriam as/os docentes a sensibilidade necessária para reconhecer as contribuições e os saberes mobilizados por esse segmento coletivo na escola. Seria possível a convivência e o respeito mútuo por parte das/os diferentes profissionais envolvidos quanto a interferência das serventes e merendeiras como educadoras na formação? Ou ainda, para que esta escuta e diálogo aconteça é necessária a aquisição de formação acadêmica e de capacitação, conquistando assim o direito de serem declaradas enquanto educadoras? E como nós, na posição de professoras/es podemos contribuir com a abertura deste espaço de reconhecimento e troca de experiências?

\section{Ensinar histórias menores: memórias e narrativas contrahegemônicas}

$\mathrm{Na}$ literatura consultada as pesquisas concluíram que é imprescindível a abertura de espaços de fala e de escuta para possibilitar a troca de conhecimento na descoberta de soluções para as auxiliares de serviços gerais lidarem com seus desafios na execução de tarefas, possibilitando maior visibilidade de suas contribuições e investimentos, e ainda, buscando em conjunto a valorização salarial e melhorias nas condições de trabalho. Tendo em vista as diferentes funções por elas desempenhadas, como reconhecê-las enquanto sujeitos que participam efetivamente do ensino em espaços informais da escola? Como romper com a hierarquia de saberes e atribuir às auxiliares de serviços gerais um espaço de protagonismo? E como o ensino de História pode contribuir neste processo?

Estas perguntas de diferentes formas tocam na questão do currículo prescrito, que rege boa parte das ações desenvolvidas no ambiente escolar. Tradicionalmente o 
conhecimento científico, sobretudo na História, temos priorizado a abordagem daquilo que Pereira (2017) denomina por história maior. Por este conceito, entende-se a preferência por esquemas explicativos na maneira de abordar os conteúdos, privilegiando as narrativas macroestruturais de acontecimentos artificialmente sequenciados, em detrimento das rupturas e das tensões entre diferentes visões de mundo que marcam a pluralidade de saberes presentes nas escolas. Ocorre, nesse sentido, a abstração da localidade no ensino, acarretando no silenciamento e na invisibilidade de grupos sociais não contemplados pela história maior. Isso ocorre porque "Quando fazemos a distinção ou hierarquização dos acontecimentos, tendemos a deixar de lado os sujeitos que foram derrotados e silenciados.”, pois “[...] a construção de conhecimento histórico educacional é um processo político de produção coletiva de significados, gestado por subjetividades, intencionalidades e relações de poder." (PAIM; ARAÚJO, 2019: 7).

Ao abordar criticamente o currículo da disciplina de História, cabe retomar as avaliações de Selva Guimarães Fonseca e Marcos Antonio da Silva (2010) acerca das mudanças, permanências, conquistas e perdas ao longo da trajetória desta disciplina. Os autores demonstram que desde a documentação que rege a política educacional até o trabalho realizado em sala de aula, a seleção dos conteúdos e a maneira de abordá-los se tornam exigências permanentes do processo pedagógico.

Isso nos remete às primeiras perguntas: Tudo é História? Se tudo é História, por que as escolas de Educação Básica são endereçados determinados conteúdos específicos, selecionados, elaborados em diferentes lugares de produção? Por que, nas diferentes realidades escolares, na construção curricular cotidiana, outros conhecimentos são selecionados e ensinados? De quais formas os currículos de História, "prescritos e vividos" operam no sentido de selecionar para que, o que e como ensinar em História? (SILVA; FONSECA, 2010: 16).

Noutro texto de sua autoria Fonseca (2006) também chama atenção para o fato de que a consciência histórica, preocupação central desta disciplina, não ganha corpo apenas com os conhecimentos socializados em sala de aula, uma vez que sua formação está em diversos lugares como na vivência escolar e em outros espaços de sociabilidade. Esta particularidade exige de nós, professoras e professores da disciplina, estabelecer uma relação viva e ativa com o tempo e com o espaço que compartilhamos, haja vista 
que "O meio no qual vivemos traz as marcas do presente e de tempos passados." (FONSECA, 2006: 127).

Como destacamos, as manifestações da colonialidades do ser, do poder e do saber são mecanismos presentes nas hierarquias que estruturam as instituições escolares e inclusive, acarretam na seleção e na abordagem dos conteúdos a serem ensinados. São marcas dos tempos passados, que se atualizam na contemporaneidade e que devem ser problematizadas em busca de uma escola mais democrática e plural. Por isso, a ruptura com a história maior neste campo disciplinar é uma forma de disseminar outra postura epistemológica, que se contrapõe à narrativa eurocentrada, desligada da realidade das/os estudantes.

Contudo, Fonseca (2006) identifica algumas das dificuldades recorrentes na abordagem da história local. Dentre elas podemos citar a excessiva fragmentação em espacialidades restritas, com periodizações particulares e problemas específicos, sem correlacionar com outros fenômenos influentes em âmbito global. Outra realidade é a reprodução de aspectos da história maior na maneira de abordar conteúdos da história local, por sua vez, descrita através de documentos oficiais, sucessões políticas e periodizações sequenciadas. Na contracorrente destas práticas, propõe uma Pedagogia da Memória.

A memória das pessoas, da localidade, dos trabalhos, das profissões, das festas, dos costumes, da cultura, das práticas políticas, está viva entre nós. Nós, professores, temos o papel de, juntos com os alunos, auscultarmos o pulsar da comunidade, registrá-lo, produzir reflexões e transmiti-lo a outros. A escola e as aulas de História são lugares de memória, da história recente, imediata e distante (FONSECA, 2006: 132).

Com base nos documentos que regem a Proposta Curricular Nacional, a abordagem de uma Pedagogia da Memória cumpre com os objetivos de lançar temáticas que partem do meio próximo das crianças e jovens, de espaços de vivência da localidade, para contemplar as problemáticas de pertencimento, identidade, pluralidade cultural étnica, religiosa e de exclusão social. Possibilitam ainda o entrecruzamento de diferentes temporalidades que se estabelecem na constituição do conhecimento histórico. Ademais, como considerou a pesquisa de Marina L. Paim (2017: 139), as/os zeladores e as serventes "trazem em suas narrativas, o conhecimento por meio das experiências adquiridas em seus trabalhos dos diferentes espaços e tempos que 
constituem o cotidiano escolar.”. Suas histórias de vida acompanham diferentes gerações que passaram pela instituição escolar e também mudanças nas formas como se estabelecem as relações na comunidade escolar. O que mudou no entorno da escola? O que se transformou no universo da cultura escolar? Quais atividades as/os estudantes exerciam nos recreios? Que profissões deixaram de existir e quais permaneceram? Por que determinadas atividades são marcadas pelas relações de gênero, classe e raça? Assim demarcamos que "O local e o cotidiano como locais de memória são constitutivos, ricos de possibilidades educativas, formativas" (FONSECA, 2006: 127).

A insurgência de narrativas contrahegemônicas de grupos subalternizados no ensino de História deve igualmente levar em consideração a coerência de uma postura ética dentro e fora da sala de aula. Sendo a consciência histórica formada por diferentes influências que se entrecruzam, é preciso levar em consideração o que Richard Keraney (2012: 419) descreveu como compaixão narrativa. Em tempos de intolerância política, religiosa, de gênero, classe e raça é crucial a defesa vigorosa da arte da escuta, da contemplação, da narração e da memória insurgente que tanto ressaltamos neste artigo. Cabe ainda, exercer a constante crítica em relação à temporalidade acelerada na escola, que obstruí o compartilhamento de experiências e a possibilidade de exercermos uma escuta crítica e atenta da/o outra/o. Entendemos que com a Pedagogia da Memória, a historiografia ganha potencial para interromper o fluxo da história maior, fazendo insurgir a multiplicidade de vozes e de sujeitos que dão corpo à escola e à comunidade local. A partir destas memórias e histórias, podemos encontrar elementos para questionar a reprodução das colonialidades do ser, do saber e do poder, que são responsáveis pela manutenção das opressões e dos privilégios no tempo presente (QUIJANO, 2007).

\section{Para não concluirmos; e, sim, para refletirmos}

Se possuímos compaixão narrativa - nos deixando ver o mundo do ponto de vista do outro - somos incapazes de matar. Se não a possuímos, somos incapazes de amar (KERANEY, 2012: 419).

Conforme explanado no decorrer deste artigo, buscamos dialogar com as narrativas orais das auxiliares de serviços gerais escolares trazendo questões cotidianas de suas memórias. Elas narraram constantes angústias relacionadas a desvalorização e a 
falta de reconhecimento. Ao mesmo tempo, em suas narrativas, destacam seu trabalho com as/os estudantes e o quanto gostam e prezam por elas/es. Suas atitudes cotidianas impulsionam as/os estudantes a olhar além das relações formais estabelecidas na escola. Através de carinho, gestos, atitudes e palavras, consideram-se mães, conselheiras e amigas.

A citação que propusemos acima expõe a urgência de mobilizarmos a compaixão narrativa que, para Kearney (2012), envolve uma postura além do altruísmo. Tanto na multiplicidade de sentidos existente nas mônadas, quanto na citação de Kearney, a compaixão narrativa se traduz nos pormenores das nossas experiências cotidianas, nas sutilezas artesanais das miudezas de nossas conversas. Desta forma, para capturarmos o que é produtivo em prol do coletivo e da ação humana, é preciso tomar distância do tempo acelerado e dos padrões impostos pela narrativa da história maior.

Também consideramos urgente olharmos para a dimensão interseccional das opressões que as auxiliares de serviços gerais da escola estão sujeitas, nos planos de classe, raça e gênero. Como destacamos, as manifestações da colonialidades do ser, do poder e do saber são mecanismos presentes nas hierarquias que estruturam as instituições escolares e acarretam na seleção e na abordagem dos conteúdos a serem ensinados. Destacamos também que é preciso buscar coerência entre as posturas epistemológicas dentro e fora da sala de aula, tendo em perspectiva uma escola mais democrática e plural.

Nesse sentido, valorizar as auxiliares de serviços gerais também atravessa a construção de uma escola com mais consciência política, o que no campo da História implica em assumir uma postura epistemológica crítica em relação aos conhecimentos tradicionalmente validados pelos currículos escolares. Nesse sentido, ao escutá-las com a devida atenção, procuramos evidenciar suas atuações nas práticas pedagógicas em espaços informais da escola. Elas não querem só respeito, mas também anseiam por valorização salarial e social. No entanto, como pudemos observar nas conversas e no entrecruzamento com a literatura consultada, elas sofrem violentos processos de precarização. Na fala delas, evidenciamos a dimensão estrutural das diferentes colonialidades e o sentimento na prática de tudo o que Benjamin diagnosticou sobre o declínio da arte de narrar, da escuta ativa e a diluição da memória que está tão impregnada em nós. $\mathrm{Na}$ contraproposta, estimulamos dentro da perspectiva historiográfica uma Pedagogia da Memória, com a insurgência de histórias menores em contraposição ao pensamento hegemônico da narrativa estrutural, distante da realidade 
das/dos estudantes e dos sujeitos presentes na comunidade escolar. Portanto, o que defendemos neste artigo é nossa luta pelo compartilhamento das experiências e o compromisso com a arte da escuta compassiva em favor de desaprender para aprendermos novamente. E, como diz Conceição Evaristo (2008), precisamos para "pôr reparo nas coisas", "assuntar a vida".

\section{Referências Bibliográficas}

CHAVES, Fátima Machado (2000). Outros olhares em escolas públicas: as relações sociais de trabalho sob a ótica de merendeiras e serventes. Trabalho \& Educação (UFMG), vol. 7: 132-157. Disponível em: 〈https://periodicos.ufmg.br/index.php/trabedu/article/view/9208>. Acesso em: 11 fev. 2021.

EVARISTO, Conceição (2008). De mãe. In: EVARISTO, C. Poemas da recordação e outros movimentos. Belo Horizonte: Nandyala.

FERNANDES, Ana Gabriela de Souza \& FONSECA, Alexandre Brasil Carvalho da \& SILVA, Adilson da (2014). Alimentação escolar como espaço para educação em saúde. Ciênc. saúde coletiva, vol. 19: 39-48, jan. Disponível em: < https://doi.org/10.1590/1413-81232014191.1711 >. Acesso em: 30 fev. 2021.

FONSECA, Selva Guimarães (2006). História local e fontes orais: uma reflexão. História Oral, vol. 9, n. 1: 125-141, jan/jun.

FREIRE, Paulo (1996). Pedagogia da Autonomia: saberes necessários à prática educativa. São Paulo: Ed. Paz e Terra.

KEARNY, Richard (2012). Narrativa. Tradução: Gilka Girardello. Revista Educação e Realidade, vol. 37, n. 2, Porto Alegre, mai./ago. Disponível em: 〈https://seer.ufrgs.br/educacaoerealidade/article/view/30354>. Acesso em: 10 mar. 2021.

LUGONES, María (2008). Colonialidad y género. Tabula Rasa, n.9: 73-101, jul./dez. Disponível em: <http://www.scielo.org.co/pdf/tara/n9/n9a06.pdf>. Acesso em: 13 mar. 2021.

NUNES, Bernadete de Oliveira (2000). O sentido do trabalho para merendeiras e serventes em situação de readaptação nas escolas públicas do Rio de Janeiro. Dissertação (Mestrado em Ciências na área da Saúde Pública) Fundação Oswaldo Cruz, Escola Nacional de Saúde Pública, Rio de Janeiro.

OLIVEIRA, Sil-Lena Ribeiro Calderaro (2018). Antes que o tempo passe tudo a raso: tambores matriarcais do grupo de Carimbó Sereia do Mar da Vila Silva em Marapanim, no Pará. Dissertação (Mestrado em Educação), Universidade Federal de Santa Catarina, Florianópolis.

PAIM, Elison Antonio \& Araújo, Helena Maria Marques (2018). Memórias outras, patrimônios outros, e decolonialidades: Contribuições teórico-metodológicas para o estudo de história da África e dos afrodescendentes e de história dos Indígenas no Brasil. Arquivos Analíticos de Políticas Educativas, vol. 26 n. 92. Disponível em: <http://dx.doi.org/10.14507/epaa.26.3543>. Acesso: 4 fev. 2021.

PAIM, Marina Luz Rotava (2017). Um olhar sensível para as narrativas e experiências de zeladores e auxiliares de serviços gerais, os agentes de serviços gerais das escolas públicas em Chapecó-SC (1970-1980): potencialidades para a produção 
de conhecimento histórico. Dissertação (Mestrado em Educação). Universidade São Francisco. Itatiba.

PEREIRA, Nilton Mullet (2017). Ensino de História e resistência: notas sobre uma história menor. In: PAIM, Elison Antonio (org.). Patrimônio cultural e escola: entretecendo saberes. Florianópolis: NUP/CED/UFSC.

PINHEIRO, Patrícia Magalhães (2021). Entre Silenciamentos e Resistências: Educação das Relações Étnico-Raciais nas Narrativas de Professoras/es de Ciências Biológicas da UFSC. Tese (Doutorado em Educação), Universidade Federal de Santa Catarina, Florianópolis.

QUIJANO, Aníbal (2007). Colonialidad del poder y clasificación social. Journal of world-systems research, vol. 11, n. 2: 342-386. Disponível em: $\langle$ http://biblioteca.clacso.edu.ar/clacso/se/20140506032333/eje1-7.pdf $>$. Acesso em: 10 fev. 2021.

SANTANA, Tatiana de Oliveira \& SANTANA, Giovanna (2019). Fontes orais e narrativas indígenas: as mônadas como possibilidade teórico-metodológica. História Oral, vol. 22: 320-339.

SILVA, Diogo Lopes (2014). Representações dos Trabalhadores não docentes no cotidiano escolar. Dissertação (Mestrado em Educação e Saúde na Infância e Adolescência). Universidade Federal de São Paulo, Escola de Filosofia, Letras e Ciências Humanas, Guarulhos.

SILVA, M. A \& FONSECA, S. G (2010). Ensino de História hoje: errâncias, conquistas e perdas. Revista Brasileira de História, vol. 30, n. 60: 13-33. Disponível em: <http://www.scielo.br/pdf/rbh/v30n60/a02v3060.pdf>. Acesso em: 7 fev. 2021.

SOUZA, Odair de (2018). A educação para as relações étnicorraciais no ensino de história: memórias e experiências de professoras na educação básica. Dissertação (Mestrado em Ensino de História), Universidade Federal de Santa Catarina, Florianópolis.

SOUZA, Técia Goulart de (2020). Educação para as relações étnico-Raciais no Centro de Ensino Fundamental Miguel Arcanjo - São Sebastião - Distrito Federal: Diálogos dentro e fora da escola. Dissertação (Mestrado em Ensino de História), Universidade Federal de Santa Catarina.

SPIVAK, Gayatri Chakravorty (2010). Pode o subalterno falar? Tradução: Sandra Regina Goulart Almeida, Marcos Pereira Feitosa, André Pereira Feitosa. Belo Horizonte: Editora UFMG.

VASCONCELOS, Ana Cláudia. L.; SILVA, Jackeline O.; MELO, Nedir S. de (2014). A astúcia invisível de mulheres trabalhadoras de escola. Psicologia em Revista, Belo Horizonte, vol. 20, n. 3: 427-445, dez. Disponível em: 〈http://dx.doi.org/DOI-10.5752/P.1678-9523.2014v20n3p427>. Acesso em: 8 fev. 2021.

VASCONCELOS, Ana. Cládia L. et al. (2002). Processo Saúde/Doença das Merendeiras e Serventes das escolas Públicas Municipais. In: I Congresso Brasileiro de extensão Universitária, João Pessoa.

Artigo recebido em 20 de abril de 2021.

Aprovado em 25 de junho de 2021.

DOI: 10.12957/intellectus.2021.58453 